"Supporting Information"

\title{
Synthesis, Characterization and Photophysics of a New Series of Anionic C,N,C Cyclometalated Platinum Complexes.
}

Jesús R. Berenguer, Elena Lalinde* and Javier Torroba.

Departamento de Química - Grupo de Síntesis Química de La Rioja, UA - C.S.I.C. Universidad de La Rioja, 26006, Logroño, Spain

* Corresponding author. E-mail: elena.lalinde@unirioja.es. 


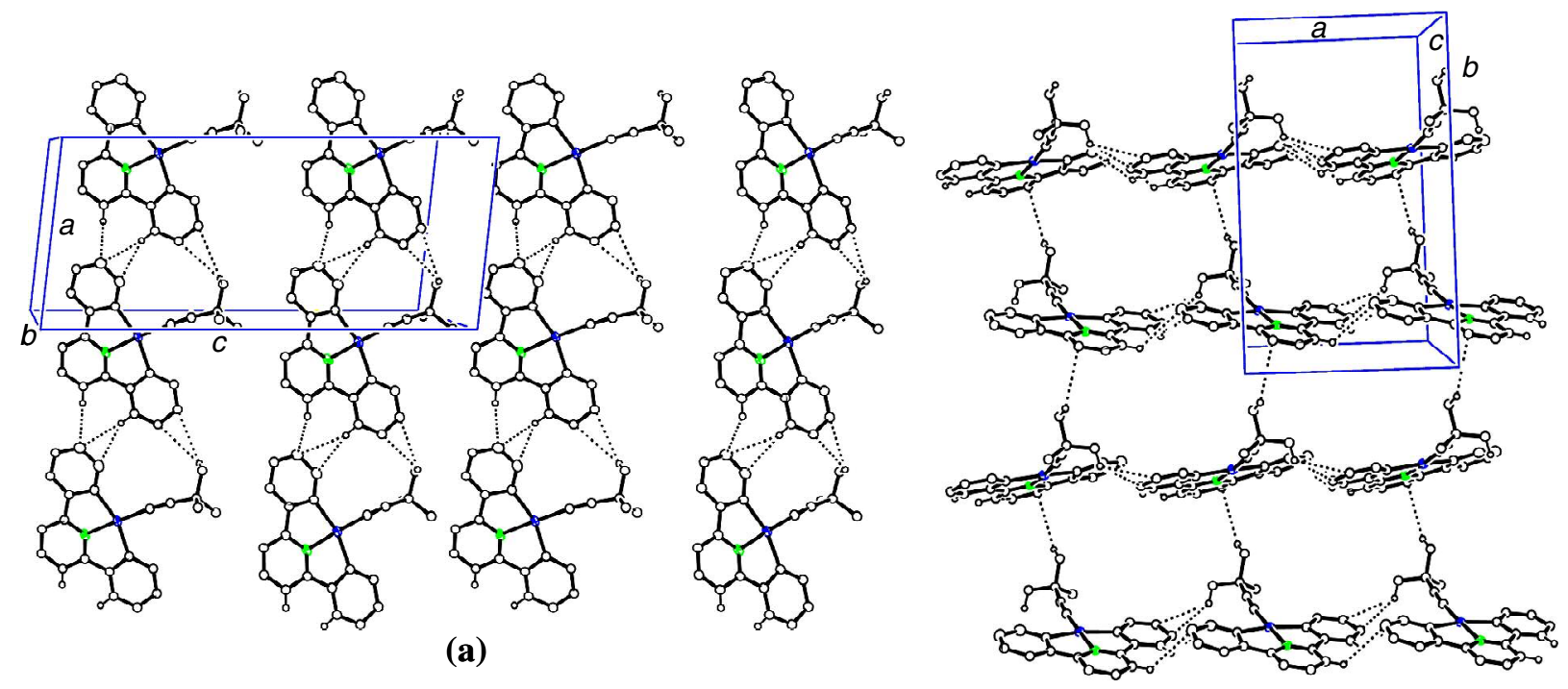

(b)

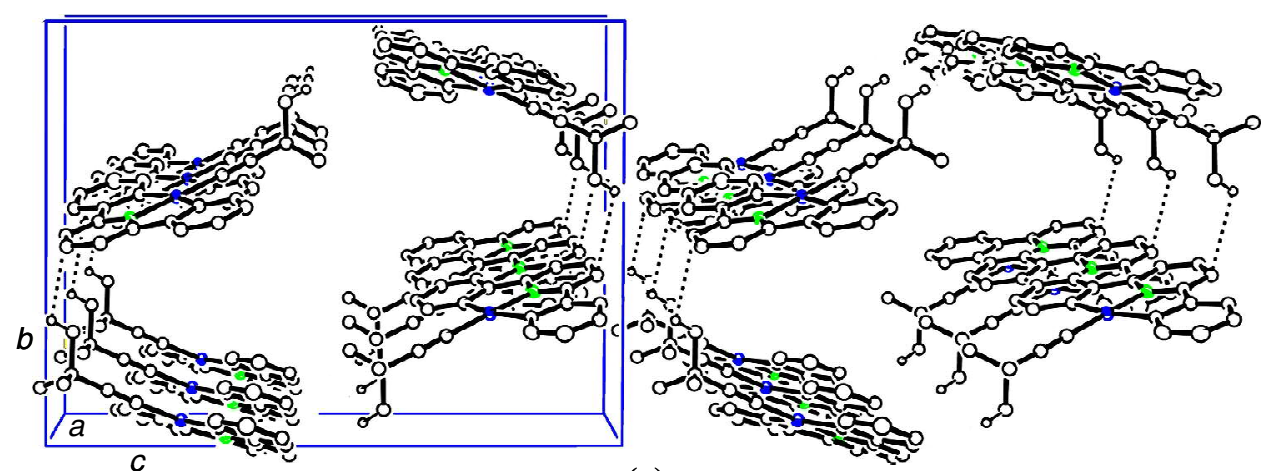

(c)

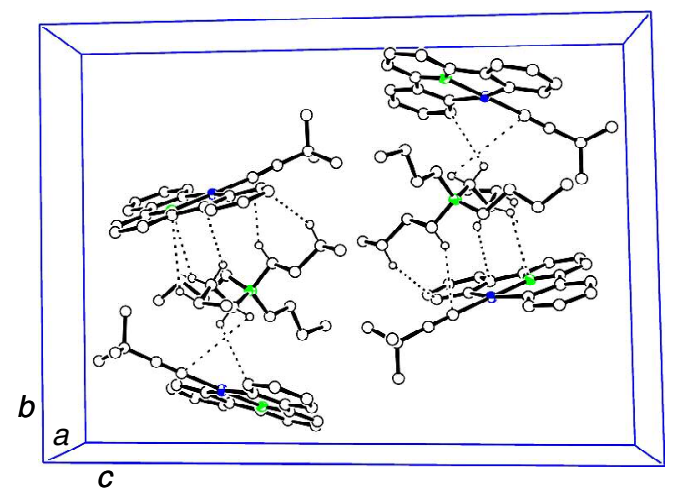

(d)

Figure S1. The molecular anions in 1 show weak C-H $\cdots \pi$ (aromatic) contacts along the $a(\mathbf{a})$ and $b$

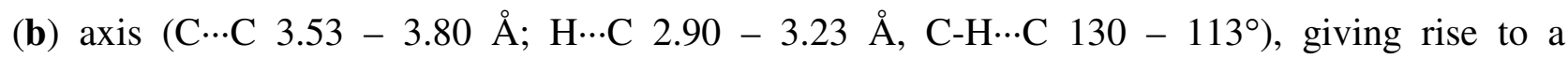
bidimensional network (c). The $\mathrm{NBu}_{4}{ }^{+}$cations accommodate in the voids generated by the supramolecular array of the anions, and present also weak hydrogen contacts with the molecular

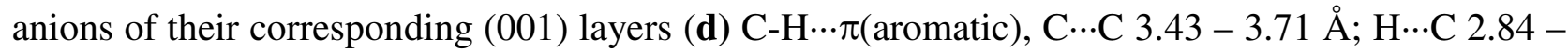
$3.09 \AA ̊ ., \mathrm{C}-\mathrm{H} \cdots \mathrm{C} 136-121^{\circ} ; \mathrm{C}-\mathrm{H} \cdots \pi(\mathrm{C} \equiv \mathrm{C}), \mathrm{C} \cdots \mathrm{C} 3.61-3.71 \AA$ А $\mathrm{H} \cdots \mathrm{C} 2.66-2.90 \AA$, C-H $\cdots \mathrm{C} 168$

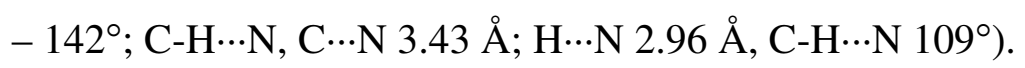



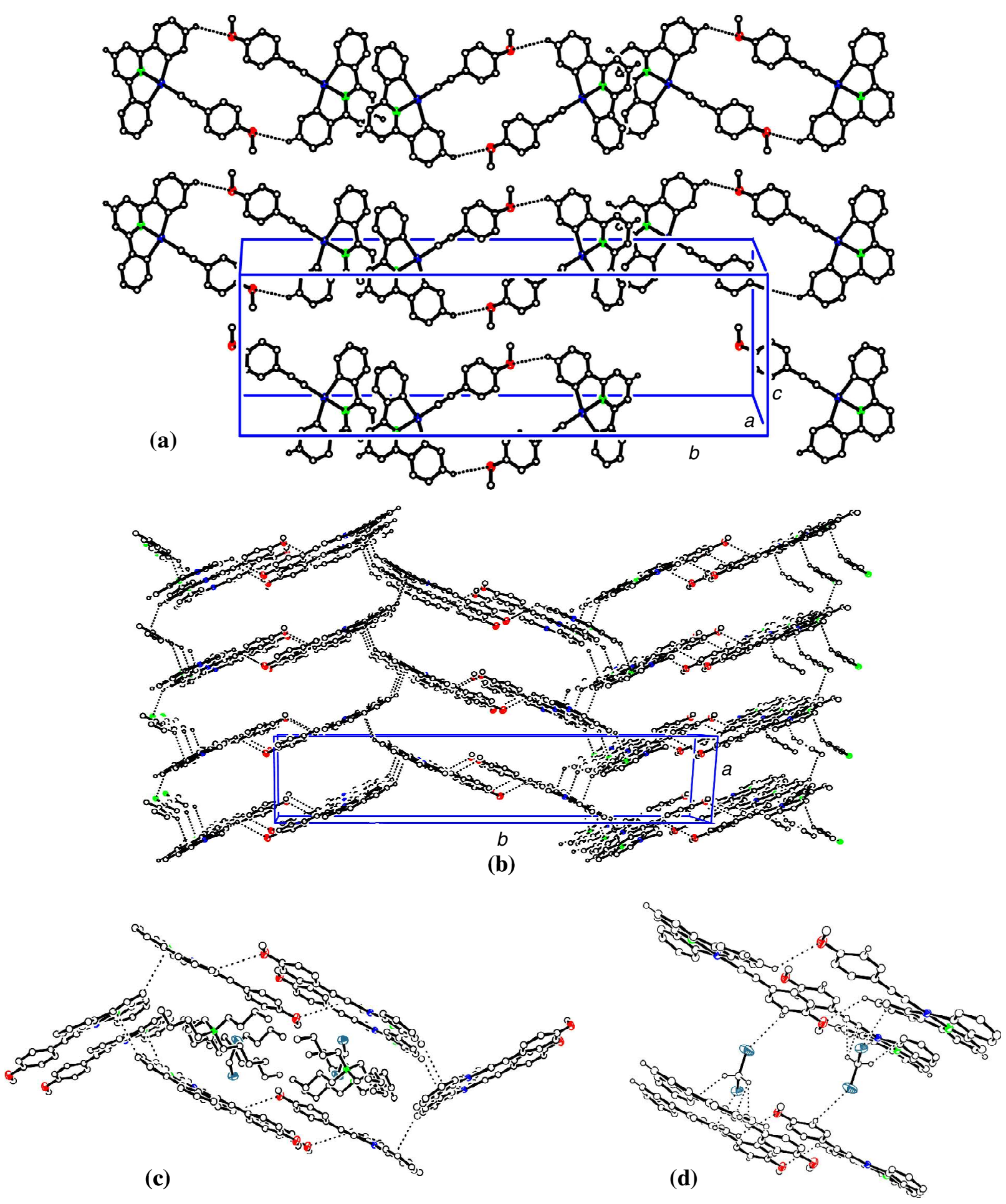

Figure S2. The molecular anions in $4 \cdot \mathrm{CH}_{2} \mathrm{Cl}_{2}$ show weak $\mathrm{C}-\mathrm{H} \cdots \pi(\operatorname{aromatic})(\mathrm{C} \cdots \mathrm{C} 3.76 \AA$; $\mathrm{H} \cdots \mathrm{C}$ $\left.2.99 \AA, \mathrm{C}-\mathrm{H} \cdots \mathrm{C} 141^{\circ}\right), \mathrm{C}-\mathrm{H} \cdots \mathrm{N}\left(\mathrm{C} \cdots \mathrm{N} 3.58 \AA ; \mathrm{H} \cdots \mathrm{N} 2.95 \AA\right.$ A, $\left.\mathrm{C}-\mathrm{H} \cdots \mathrm{N} 126^{\circ}\right)$ and $\mathrm{C}-\mathrm{H} \cdots \mathrm{O}(\mathrm{C} \cdots \mathrm{O}$ $3.75 \AA$; $\mathrm{H} \cdots \mathrm{O} 3.22 \AA, \mathrm{C}-\mathrm{H} \cdots \mathrm{O} 118^{\circ}$ ) contacts along the $a$ and $b$ axis, giving rise to a bidimensional network $(\mathbf{a}, \mathbf{b})$. The $\mathrm{NBu}_{4}{ }^{+}$cations and $\mathrm{CH}_{2} \mathrm{Cl}_{2}$ molecules accommodate in the voids generated by the supramolecular array of the anions (c), and present also weak hydrogen contacts with the molecular anions of different (001) layers building a final tridimensional network (C-

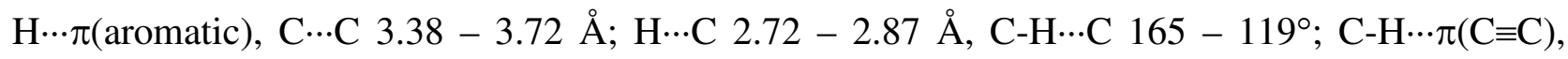




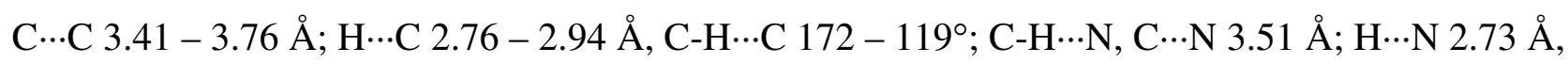

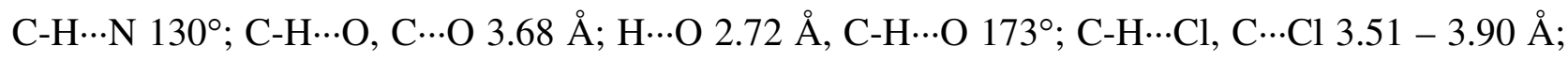
$\mathrm{H} \cdots \mathrm{Cl} 2.89-3.12 \AA, \mathrm{C}-\mathrm{H} \cdots \mathrm{Cl} 157-112^{\circ}$ ). Figure S2d shows the hydrogen contacts around the $\mathrm{CH}_{2} \mathrm{Cl}_{2}$ molecules. 

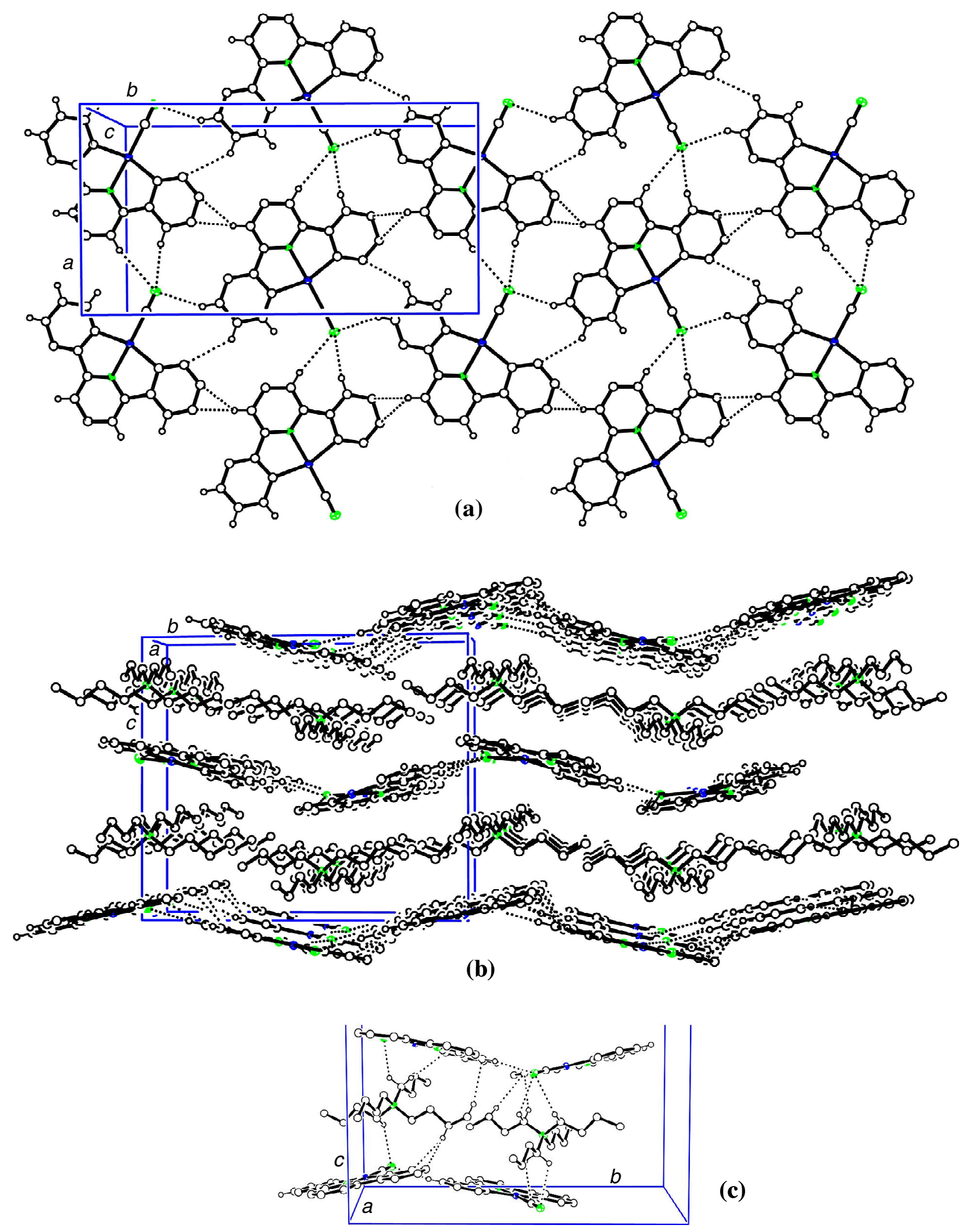

(c)

Figure S3. The molecular anions in $\mathbf{5}$ package into (001) crystallographic layers showing weak C-

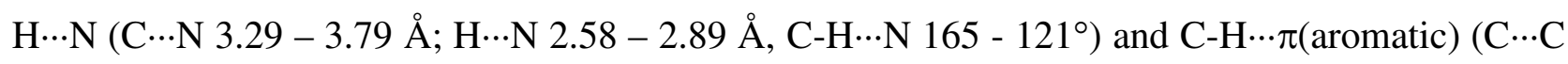
$3.58-3.76 \AA$; H $\cdots \mathrm{C} 2.66-3.09 \AA, \mathrm{C}-\mathrm{H} \cdots \mathrm{C} 144-124^{\circ}$ ) contacts (a). The space between the layers of the anions is filled by layers of $\mathrm{NBu}_{4}{ }^{+}$cations (b), which also present weak hydrogen contacts with the molecular anions of different layers (c), building a final tridimensional network (C- 


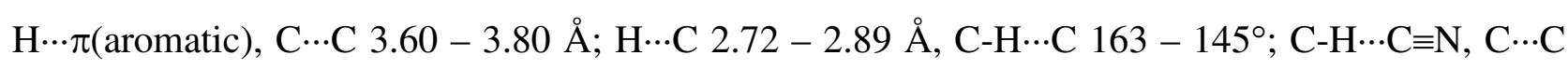

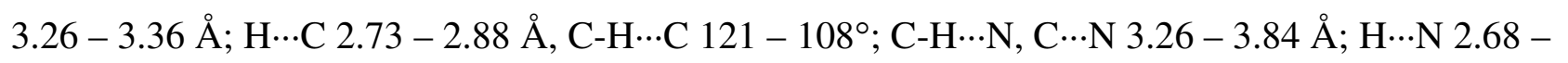
$2.83 \AA$, C-H $\left.\cdots \mathrm{N} 156-113^{\circ}\right)$. 

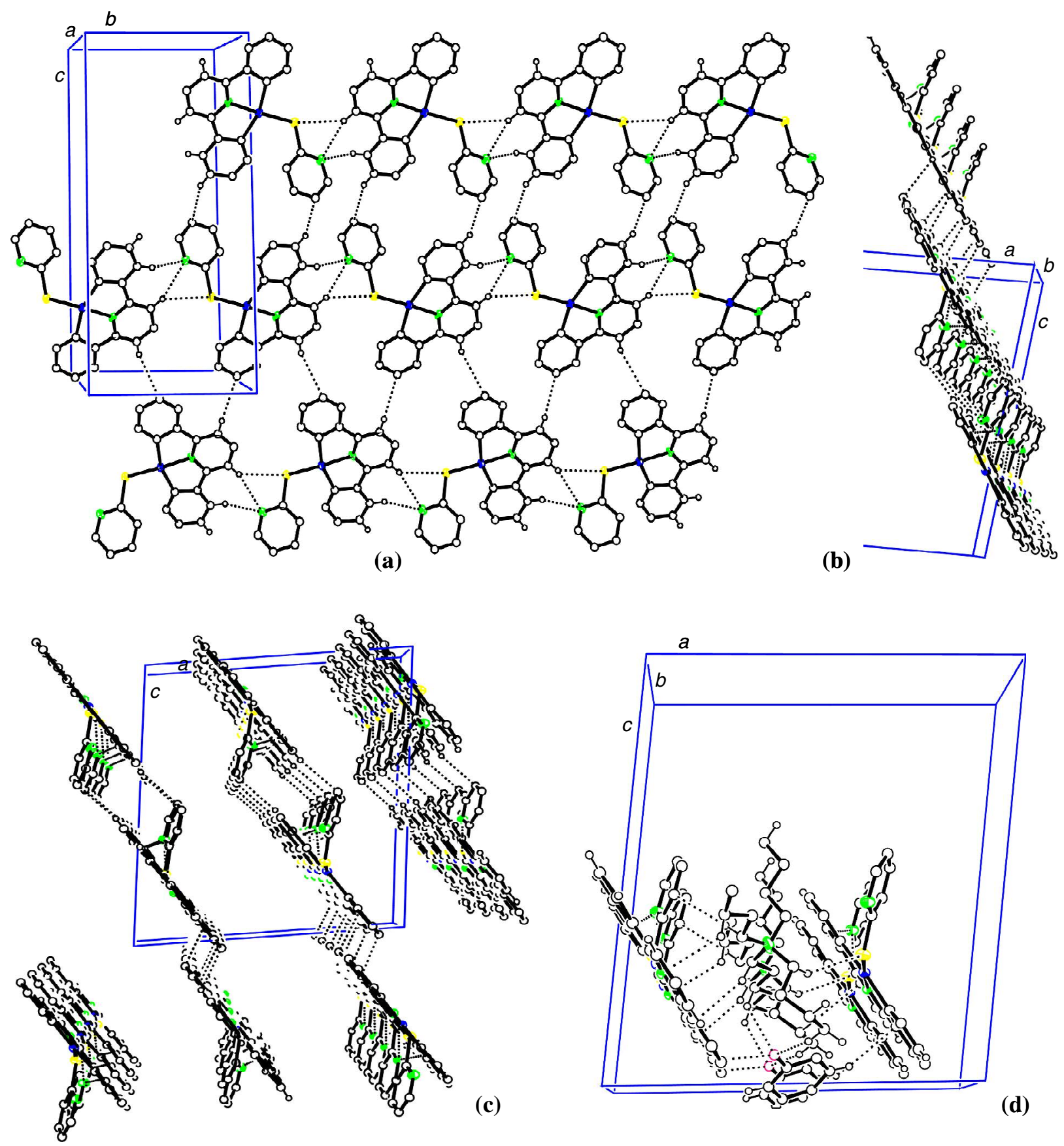

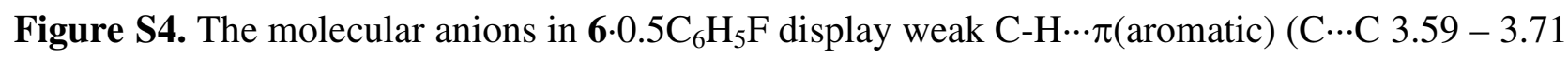

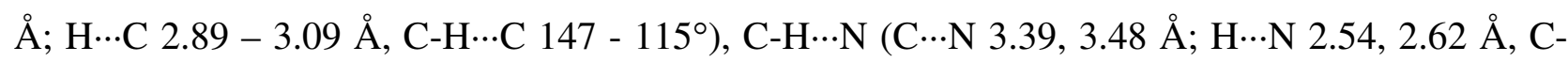
$\left.\mathrm{H} \cdots \mathrm{N} 153^{\circ}\right)$ and $\mathrm{C}-\mathrm{H} \cdots \mathrm{S}\left(\mathrm{C} \cdots \mathrm{S} 3.76 \AA\right.$; H $\cdots \mathrm{S} 3.00 \AA$, C-H $\left.\cdots \mathrm{S} 141^{\circ}\right)$ contacts (a), giving rise to a bidimensional arrangement of the anions in the (302) crystallographic orientation (a,b). The space between the layers of anions (c) is filled by the $\mathrm{NBu}_{4}{ }^{+}$cations and the $\mathrm{C}_{6} \mathrm{H}_{5} \mathrm{~F}$ crystallization molecules, which also present weak hydrogen interactions, between them and with the molecular anions of different (302) layers (d), building a final tridimensional network $(\mathrm{C}-\mathrm{H} \cdots \pi$ (aromatic),

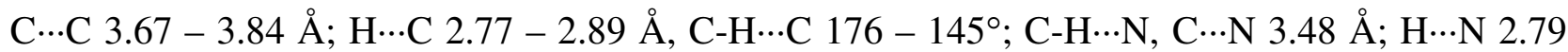




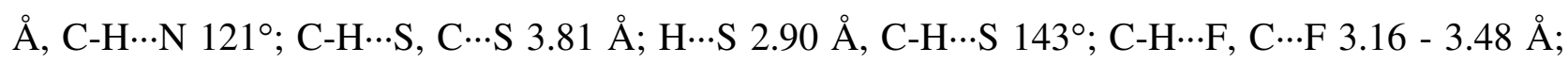

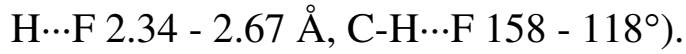




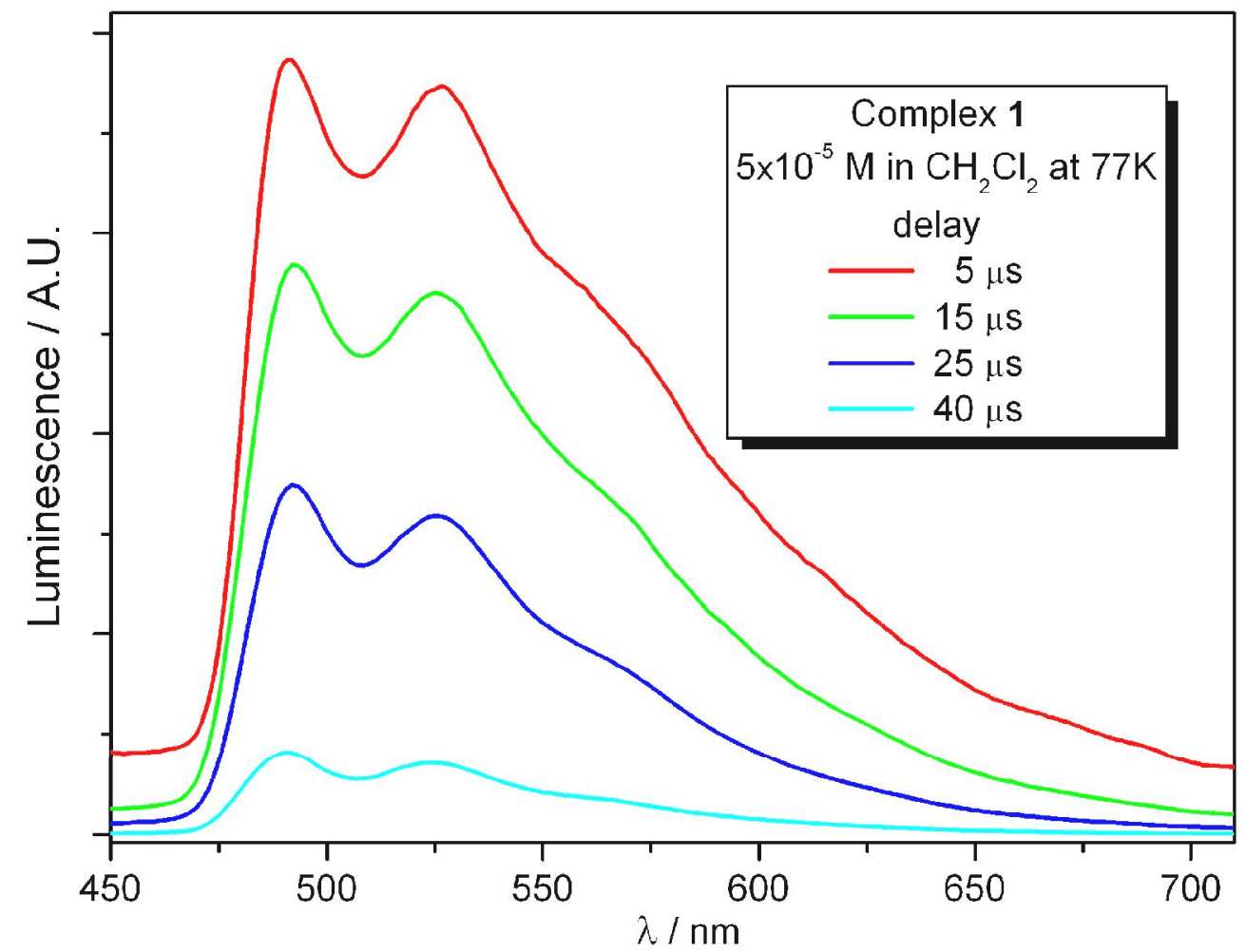

Figure S5. Time-resolved emission profiles for complex $\left(\mathrm{NBu}_{4}\right)\left[\mathrm{Pt}\left(\mathrm{C}^{\wedge} \mathrm{N}^{\wedge} \mathrm{C}\right)\left(\mathrm{C} \equiv \mathrm{C}^{\mathrm{t}} \mathrm{Bu}\right)\right](\mathbf{1})$ in $5 \times 10^{-5} \mathrm{M} \mathrm{CH}_{2} \mathrm{Cl}_{2}$ solution at $77 \mathrm{~K}$.

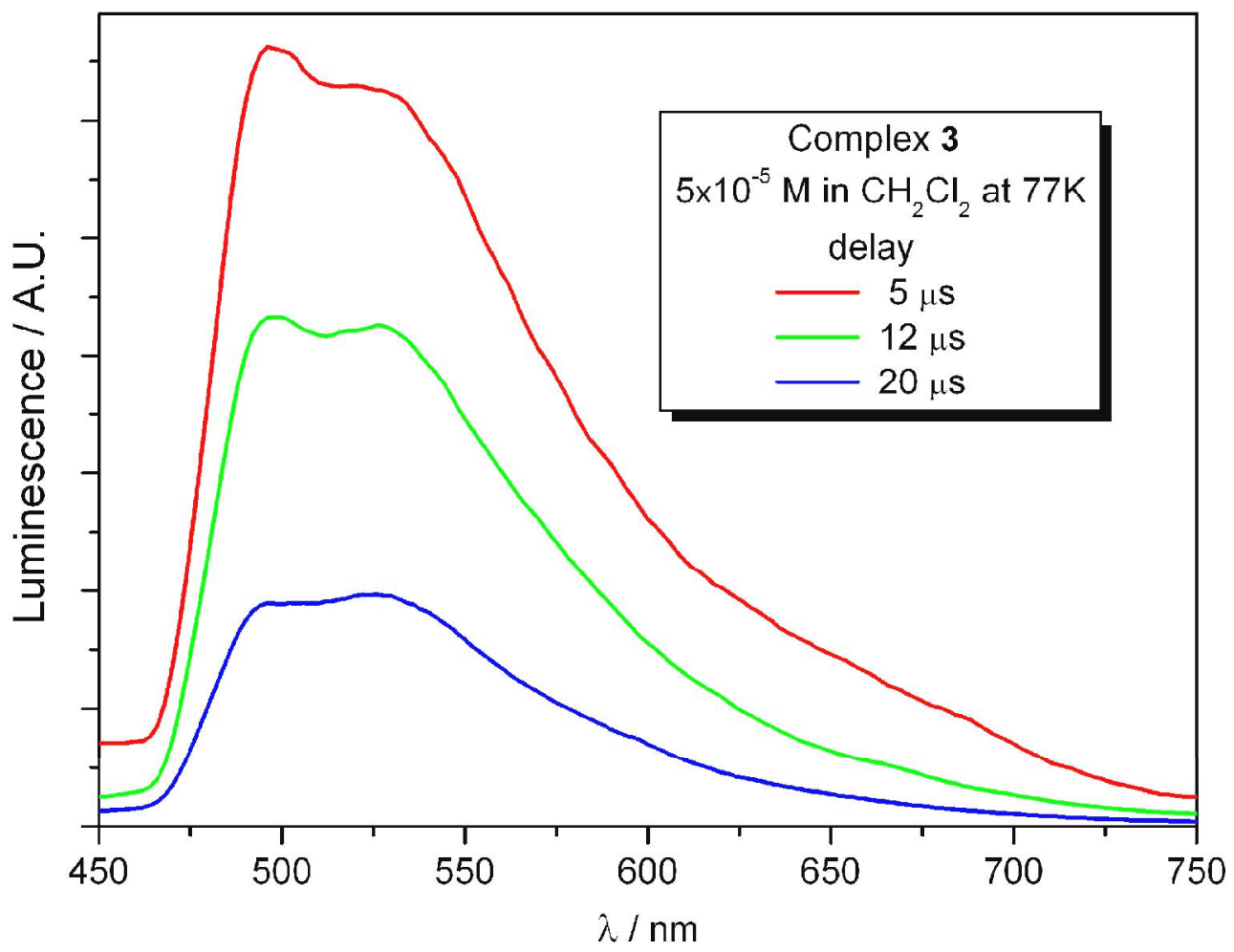

Figure S6. Time-resolved emission profiles for complex $\left(\mathrm{NBu}_{4}\right)\left[\operatorname{Pt}\left(\mathrm{C}^{\wedge} \mathrm{N}^{\wedge} \mathrm{C}\right)(\mathrm{C} \equiv \mathrm{CTol})\right](\mathbf{3})$ in $5 \times 10^{-5} \mathrm{M} \mathrm{CH}_{2} \mathrm{Cl}_{2}$ solution at $77 \mathrm{~K}$. 


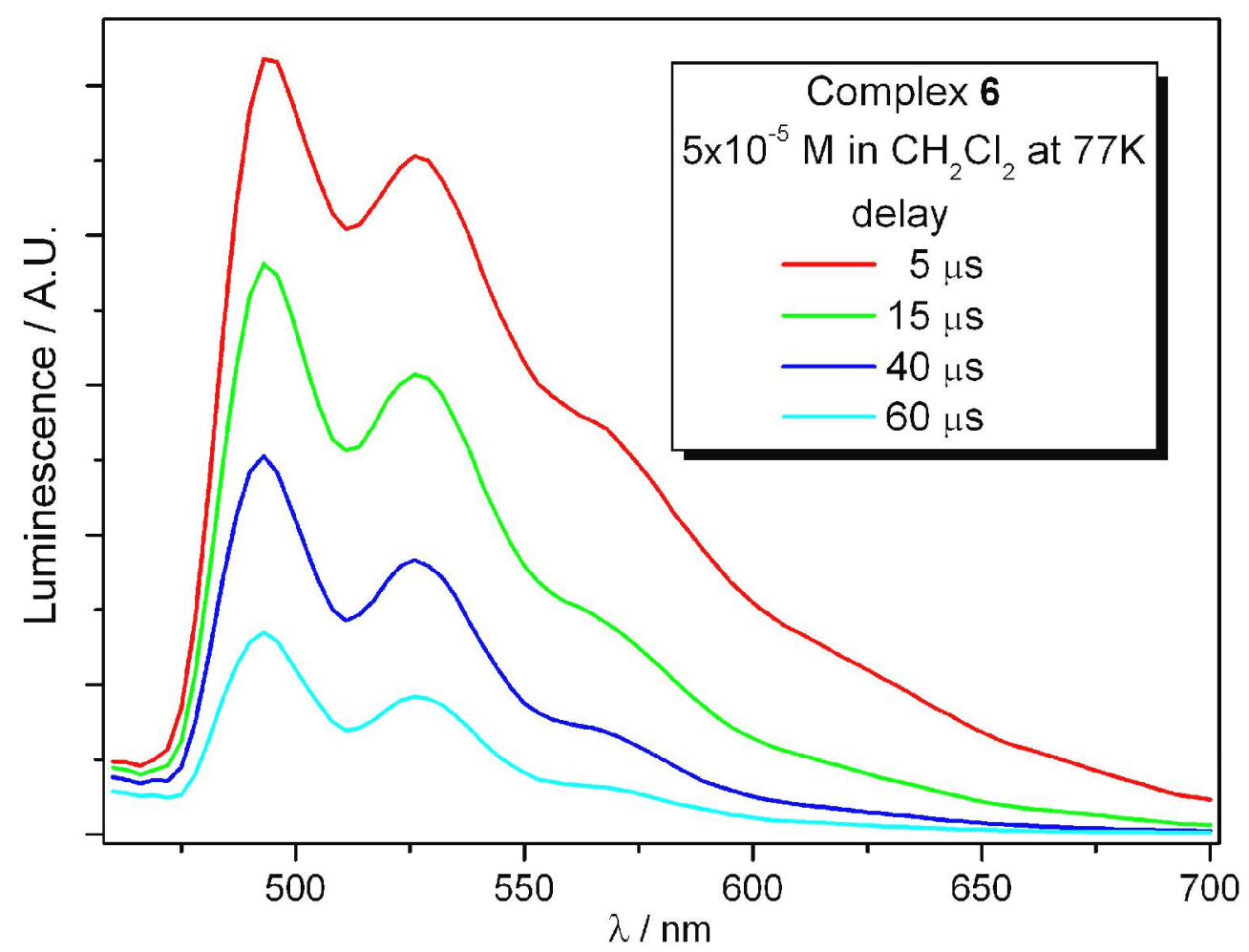

Figure S7. Time-resolved emission profiles for complex $\left(\mathrm{NBu}_{4}\right)\left[\mathrm{Pt}\left(\mathrm{C}^{\wedge} \mathrm{N}^{\wedge} \mathrm{C}\right)(\mathrm{S}-2 \mathrm{Py})\right](6)$ in $5 \times 10^{-5}$ $\mathrm{M} \mathrm{CH}_{2} \mathrm{Cl}_{2}$ solution at $77 \mathrm{~K}$.

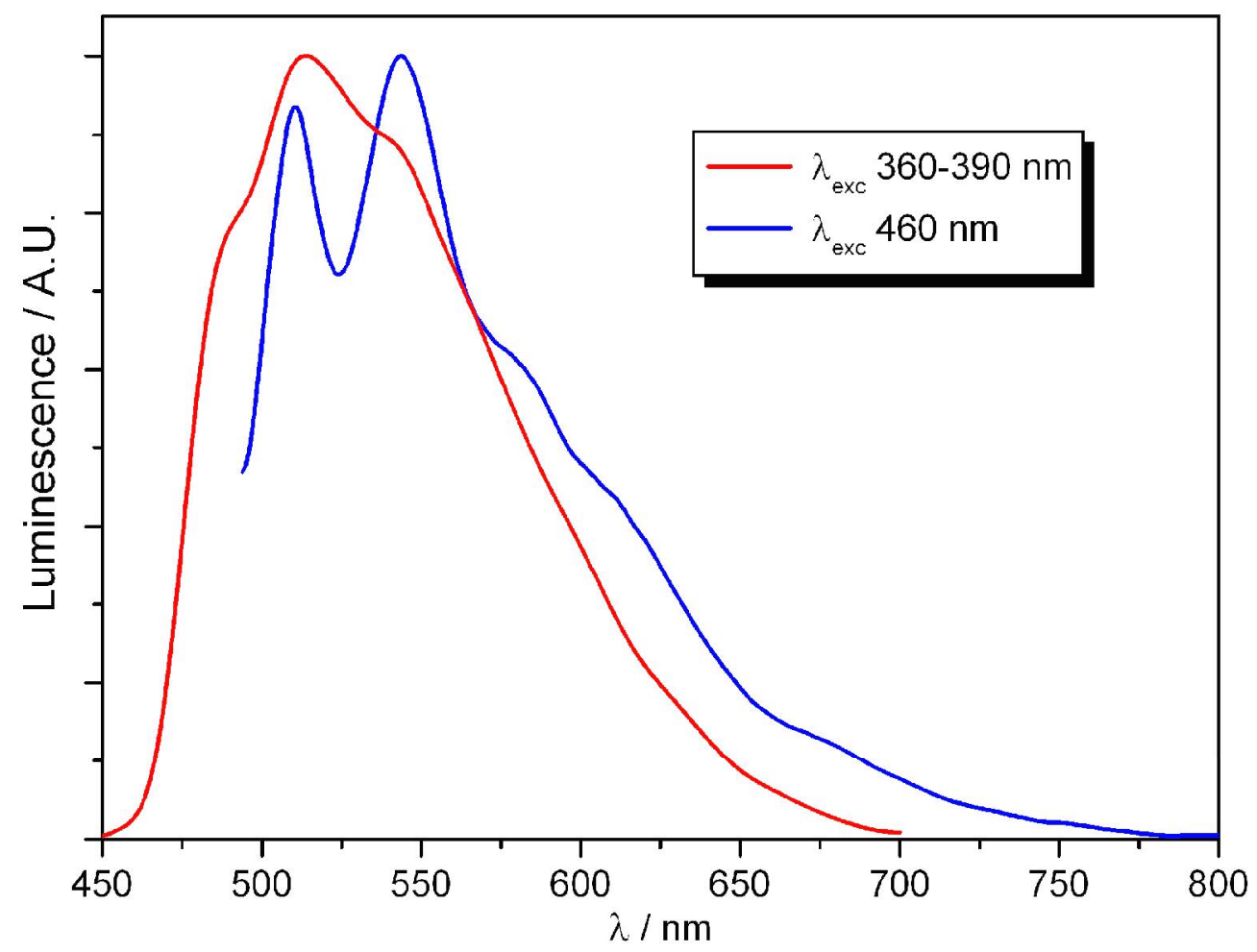

Figure S8. Steady-state spectra of complex $\left(\mathrm{NBu}_{4}\right)\left[\mathrm{Pt}\left(\mathrm{C}^{\wedge} \mathrm{N}^{\wedge} \mathrm{C}\right)\left(\mathrm{CH}_{2} \mathrm{COCH}_{3}\right)\right]$ (7) with different excitation wavelengths in $5 \times 10^{-5} \mathrm{M} \mathrm{CH}_{2} \mathrm{Cl}_{2}$ solution at $77 \mathrm{~K}$. 